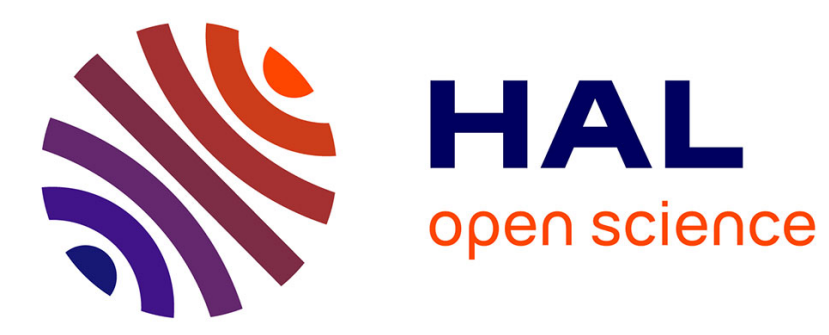

\title{
FMR and Static Magnetic Properties of Gallium Substituted Magnetoplumbite
}

\author{
M. Marysko, Z. Frait, S. Krupicka
}

\section{To cite this version:}

M. Marysko, Z. Frait, S. Krupicka. FMR and Static Magnetic Properties of Gallium Substituted Magnetoplumbite. Journal de Physique IV Proceedings, 1997, 07 (C1), pp.C1-347-C1-348. 10.1051/jp4:19971140 . jpa-00254784

\section{HAL Id: jpa-00254784 https://hal.science/jpa-00254784}

Submitted on 1 Jan 1997

HAL is a multi-disciplinary open access archive for the deposit and dissemination of scientific research documents, whether they are published or not. The documents may come from teaching and research institutions in France or abroad, or from public or private research centers.
L'archive ouverte pluridisciplinaire HAL, est destinée au dépôt et à la diffusion de documents scientifiques de niveau recherche, publiés ou non, émanant des établissements d'enseignement et de recherche français ou étrangers, des laboratoires publics ou privés. 


\title{
FMR and Static Magnetic Properties of Gallium Substituted Magnetoplumbite
}

\author{
M. Maryško, Z. Frait* and S. Krupiłka \\ Institute of Physics AS CR, Cukrovarnická 10, 16200 Praha 6, Czech Republic \\ * Institute of Physics AS CR, Na Slovance 2, 18040 Praha 8, Czech Republic
}

\begin{abstract}
Magnetization and uniaxial anisotropy were studied on single crystals of $\mathrm{PbFe}_{12-x} \mathrm{Ga}_{\mathrm{x}} \mathrm{O}_{19}$, where $\mathrm{x}=0$ 8 from 2 to $360 \mathrm{~K}$. The results suggest that for $x>3$ the spin arrangement becomes non-collinear. The magnetic moment and anisotropy for $\mathrm{x}<3$ are roughly consistent with the random distribution of $\mathrm{Ga}^{3+}$ ions in all sites except for $2 b$ : For $x=5.94$ and 8.02 the relatively large anisotropy of the Curie temperature was found. The FMR measurements at $\mathrm{T}=300 \mathrm{~K}$ were interpred using the g-tensor formulation.
\end{abstract}

\section{INTRODUCTION}

We are concerned with the single crystals of the magnetoplumbite $\mathrm{PbFe}_{12 . x} \mathrm{Ga}_{x} \mathrm{O}_{19}$ substituted by gallium. Although the preparation and some properties of these materials have been reported earlier [1-3], detailed work on this subject was absent. In addition to it the first FMR experiments made for $\mathrm{x} \leq 3.1$ did not allow to make the definite conclusions on this system. The purpose of this article is to report the static as well as the FMR measurements performed on additional samples especially, with larger Ga content.

\section{EXPERIMENT AND RESULTS}

The single crystals of $\mathrm{PbFe}_{12-x} \mathrm{Ga}_{x} \mathrm{O}_{19}$ (for $\mathrm{x}$ see Tab. 1) were prepared by the flux method [3]. The samples used in experiments were platelets of about square form with the transversal dimensions $1.5-2 \mathrm{~mm}$ and thickness $50-150 \mu \mathrm{m}$. They were obtained by splitting and polishing so that the surface of the platelet was perpendicular to the hexagonal $c$ axis.

The static measurements were performed by the magnetometer Quantum Design MPMS-5S. We measured the magnetization curves in easy and hard directions i.e. with the static magnetic field along (\|) and perpendicular ( 1 ) to the $\mathrm{c}$ axis respectively. The temperature range was from $\mathrm{T}=2$ to $360(400) \mathrm{K}$. In the field region $30-50 \mathrm{kOe}$ the susceptibility of the paraprocess $\chi_{p}$ was evaluated. At $T=2 \mathrm{~K}$ we find $\left(\chi_{\mathrm{p}}\right) \| \approx\left(\chi_{\mathrm{p}}\right) \perp<10^{.5}$ for $\mathrm{x}=0 ; 1.21$ and 2.3.10 $10^{-5} ; 3.34 .10^{-5} ; 1.07 .10^{-4}$; $1.72 .10^{-4} ; 3.10^{-4}$ for $x=3.1 ; 4.49 ; 5.94 ; 8.02$ respectively. For $x \leq 3.1 \chi_{p}$ increases markedly with increasing temperature whereas for $x \geq 4.49 \chi_{p}$ becomes nearly temperature independent. The saturation magnetization $M_{s}$ was determined by extrapolating the magnetization curves to $\mathrm{H}=0$ and for $T>0.85 \mathrm{~T}_{\mathrm{c}}$ using the Arrot plot $\mathrm{M}^{2}$ vs $\mathrm{M} / \mathrm{H}$. For $\mathrm{H}>15 \mathrm{kOe}$ this plot corresponding to the $(\|)$ and $(\perp)$ direction was linear and we could evaluate $\left(M_{s}\right),\left(F i g .1\right.$ a), $\left(M_{s}\right) \perp$ and the Curie temperatures $\left(T_{c}\right)_{1},\left(T_{c}\right)_{1}$ in the standard way. For $x=4.49$ we find $\left(T_{c}\right)_{1} \approx\left(T_{c}\right)_{1} \approx 416.5 \pm 0.5 \mathrm{~K}$ by extrapolating from the region $T \leq 400 \mathrm{~K}$. In contrast to it, for $x=5.94$ and 8.02 we get the anisotropic Curie temperature, namely $\left(T_{c}\right), \approx$ $322 \pm 2 \mathrm{~K},\left(\mathrm{~T}_{0}\right)_{1} \approx 312 \pm 2.5 \mathrm{~K}$ for $\mathrm{x}=5.94$ and $\left(\mathrm{T}_{\mathrm{c}}\right)_{1} \approx 127 \pm 5 \mathrm{~K},\left(\mathrm{~T}_{\mathrm{c}}\right)_{1} \approx 104 \pm 2 \mathrm{~K}$ for $\mathrm{x}=8.02$. A similar behaviour is observed for the paramagnetic Curie temperatures determined from the $1 / \chi$ vs $\mathrm{T}$ plots. The uniaxial anisotropy fields were evaluated from the slopes $\mathrm{s}$ of the $(1)$ magnetization curves at $\mathrm{H}=0$ using the relation $2 \mathrm{~K}_{1} / \mathrm{M}_{\mathrm{s}}=\mathrm{M}_{\mathrm{s}} / \mathrm{s}$. (Fig. $1 \mathrm{~b}$ ).

The (li) and ( 1 ) FMR measurements were performed at frequencies $46.6 ; 59.5 ; 69.5 ; 79.5$ and $50.6 ; 59 \mathrm{GHz}$ respectively. From the measured resonance fields we evaluated the components of the $\mathrm{g}$ tensor $\mathrm{g} \|, \mathrm{g} \perp$ and the effective anisotropy fields $H_{1}$ eff, $H_{1}$ eff, where $H_{4}$ eff $=2 K_{1} / M_{3}-4 \pi M_{3}$ (4). For $x \leq 4.49$ the peak-to-peak FMR linewidth $\Delta H_{1}$ varies from about $100 \mathrm{Oe}(46 \mathrm{GHz})$ to $150-250 \mathrm{Oe}(69 \mathrm{GHz})$, the corresponding $\Delta \mathrm{H}_{\perp}$ values being roughly two times larger. For $x=5.94$ we obtain $\Delta H_{I} \approx 800$ Oe which is relatively independent on frequency $\left(\Delta H_{1} \approx 600 \mathrm{Oe}\right)$.

\section{DISCUSSION}

The behaviour of $\chi_{p}$ suggests that for $x>3$ the arrangement of the spins becomes non-collinear and therefore we limit ourseif, in the quantitative considerations, to the region $x<3$. Here the dependence of the measured magnetic moment $n$ and constant $K_{1}$ on $x$ (Fig. 1 b) at $T=2 \mathrm{~K}$ will be compared with the theoretical functions $n(x), K_{1}(x)$ (the single-ion contributions $\Delta K_{1}$ taken from [5] and $n(0), K_{1}(0)$ fitted to the experiment). 


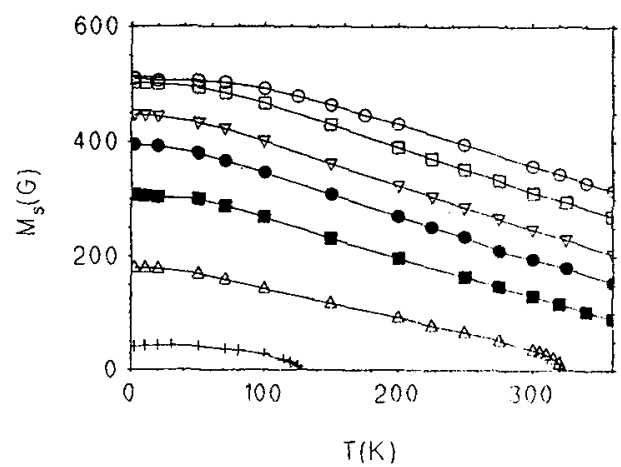

a)

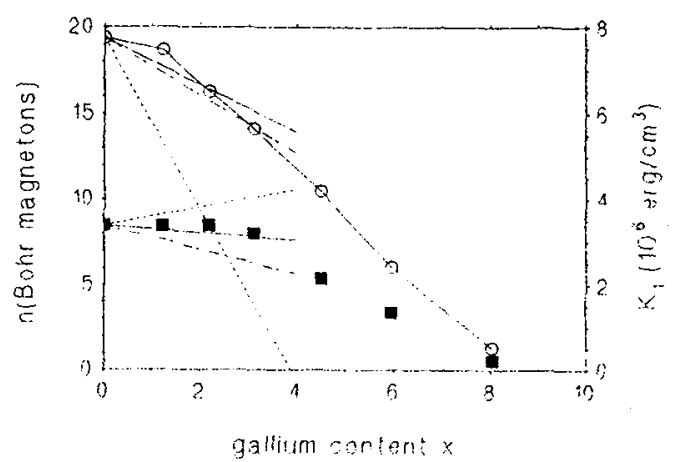

b)

Figure: 1: a) Temperature dependence of the saturation magnetization $\left(M_{s}\right)_{1}$ for $x=0(0) \div 8.02(+)$.

b) Measurement at $T=2 \mathrm{~K}$ - magnetic moment per formula unit $(0), K_{1}$ ( $)$ ) as functions of $x$; straight lines correspond to different distributions of $\mathrm{Ga}^{3+}$ ions.

Tab. 1. Data at $\mathrm{T}=300 \mathrm{~K}$.

\begin{tabular}{|c|c|c|c|c|c|c|c|}
\hline $\mathbf{x}$ & $\mathbf{g} \|$ & $g \perp$ & $\mathrm{H}_{1}^{\text {effr( }}(\mathrm{Oe})$ & $\mathrm{H}_{1}{ }^{\mathrm{eff}}(\mathrm{Oe})$ & $4 \pi \mathrm{M}_{0}(\mathrm{G})$ & $2 \mathrm{~K}_{1} / \mathrm{M}(\mathrm{Oe})$ & $\left(\mathrm{H}_{\perp} \mathrm{em}_{\mathrm{s}}(\mathrm{Oe})\right.$ \\
\hline 0 & 1.982 & 1.959 & 9794 & 9135 & 4499 & 13930 & 9431 \\
\hline 1.21 & 1.982 & 1.954 & 11513 & 11038 & 3908 & 14739 & 10831 \\
\hline 2.19 & 1.915 & 1.955 & 14664 & 13220 & 3104 & 16209 & 13105 \\
\hline 3.1 & 1.906 & 1.986 & 15921 & 15340 & 2450 & 17727 & 15277 \\
\hline 4.49 & 2,000 & 1.976 & 13126 & 13060 & 1621 & 16797 & 15176 \\
\hline 5.94 & 1.914 & 1.912 & 13287 & 12526 & 447 & 11374 & 10927 \\
\hline
\end{tabular}

For the distribution of the $\mathrm{Ga}^{3+}$ ions among $12 \mathrm{k}$ and 2 a sites [6], among all the sites and among all the sites, except for the $2 \mathrm{~b}$ sites [7] we obtain the dotted, dashed-dotted and dashed straight lines respectively. From these three distributions relatively the best agreement occurs for the latter case.

We regard as an interesting fact the relatively large anisotropy of the Curie temperature ( $\Delta \mathrm{Tc}$ up to $23 \mathrm{~K}$ ) observed for $\mathrm{x}=5.94$ and 8.02. A similar but smaller effect of this kind was reported for $\mathrm{PbFe}_{12} \mathrm{O}_{19}[8]\left(\Delta \mathrm{T}_{c} \approx 1.2 \mathrm{~K}\right)$ and $\mathrm{BaFe} \mathrm{e}_{12} \mathrm{O}_{19}[9]$ $\left(\Delta \mathrm{T}_{\mathrm{c}}=\approx 3.8 \mathrm{~K}\right)$. For a ferromagnet the anisotropy of $\mathrm{T}_{c}$ should appear for the ratio $\lambda$ of the anisotropy to exchange energy comparable to unity [10], which is not our case $\left(\lambda \approx 10^{-2}\right)$. Abrupt increase of $\Delta$ Tc when going from $x=4.49$ to 5.94 suggests, however, that the observed effect may be, in a way, connected with increasing disordering of the magnetic system for the large dilution by nonmagnetic $\mathrm{Ga}^{3+}$ ions. This conjecture is also supported by the fact that an unexpected increase of $\Delta H$ was found just for $x=5.94$.

For $x \leq 3.1$ the fields $H_{\perp}$ eff, $H_{1}$ eff agree relatively well with the values of $\left(H_{\perp} \text { eff }\right)_{s}$ which are calculated from $2 K_{1} / M_{8}$ and $4 \pi \mathrm{M}_{3}$ (Tab. 1). In accord with [4] this agreement is better just for $\mathrm{H}_{1}$ eff. The disagreement for $\mathrm{x}=4.49$; 5.94 is probably connected with a non-collinear arrangement. Analogously as for $\mathrm{BaFe}_{12-x} \mathrm{Ga}_{\mathrm{x}} \mathrm{O}_{19}$ [11] we find a frequency independent part of $\Delta H$ due to inhomogeneities. For $x=5.94$, where $\mathrm{M}_{\mathrm{s}}$ is small, the large value of this contribution is likely to be caused by fluctuations in $K_{1}$ and $g_{1}, g_{1}$.

\section{References}

[1] Krupicka S., Pollert E. and Zounová F., Proc. 6th conf. of czechosl. phys., Ostrava 1979, 07-25 (in czech).

[2] Maryško M., Frait Z., Krupička S., Nevřiva M., Pollert E., Czech J. Phys. B29 (1979) 1313-1316.

[3] Pollert E., Nevrriva M., Matějková L., Novák J., Mat. Res. Bull. 16(1981) 1499-1504.

[4] Silber L.M., J. Appl. Phys. 44(1973) 1855-1863.

[5] You Xu, Gui-ling Yang, Da-ping Chu and Hong-ru Zhai, phys. stat. sol. (b) 157(1990) 685-693.

[6] Štěpánková H., Englich J., Lütgemeier H., IEEE Trans. Magnetics, 30(1994) 988-990.

[7] Albanese G., Carbucicchio M. and Deriu A., Nuovo Cimento 15 B (1973) 147-158.

[8] Aléonard R., Bloch D. and Boutron P., C.R. Acad. Paris, 263(1966) 951-954.

[9] Belov K.P., Jergin Yu. V., Koroleva L.I., Levitin R.Z, and Pedko A.V., phys. stat. sol. 12(1965) $219-224$.

[10] Callen E.R., Phys. Rev. 124(1961) 1373-1379.

[11] Röschmann P., Lemke M., Tolksdorf W. and Welz F., Mat. Res. Bul. 19(1984) 385-392. 